\title{
Validation of Bmi1 as a Therapeutic Target of Hepatocellular Carcinoma in Mice
}

\author{
Shibo Qi ${ }^{1, \dagger}$, Bin Li ${ }^{1, \dagger}$, Tan Yang ${ }^{1}$, Yong Liu ${ }^{1}$, Shanshan Cao ${ }^{1}$, Xingxing He ${ }^{2}$, Peng Zhang ${ }^{3}$, \\ Lei $\mathrm{Li}^{1}$ and Chuanrui $\mathrm{Xu}{ }^{1, *}$
}

1 School of Pharmacy, Tongji Medical College, Huazhong University of Science and Technology, Wuhan 430030, China; E-Mails: qi601960314@gmail.com (S.Q.); tjlibin@hust.edu.cn (B.L.); M201475282@hust.edu.cn (T.Y.); liuxiulank1@gmail.com (Y.L.); M201475285@hust.edu.cn (S.C.); M201475065@hust.edu.cn (L.L.)

2 Department of Hepatology, Tongji Medical College, Huazhong University of Science and Technology, Wuhan 430030, China; E-Mail: xxhe@tjh.tjmu.edu.cn

3 Department of Oncology of Tongji Hospital, Tongji Medical College, Huazhong University of Science and Technology, Wuhan 430030, China; E-Mail: pengzhang@tjh.tjmu.edu.cn

$\dagger$ These authors contributed equally to this work.

* Author to whom correspondence should be addressed; E-Mail: xcr@hust.edu.cn; Tel.: +86-189-7165-7560.

External Editor: William Cho

Received: 23 August 2014; in revised form: 12 October 2014/ Accepted: 23 October 2014 / Published: 3 November 2014

\begin{abstract}
Bmil is a member of the polycomb group family of proteins, and it drives the carcinogenesis of various cancers and governs the self-renewal of multiple types of stem cells. Our previous studies have revealed that Bmil acts as an oncogene in hepatic carcinogenesis in an INK4a/ARF locus independent manner. However, whether Bmil can be used as a potential target for hepatocellular carcinoma treatment has not been fully confirmed yet. Here, we show that perturbation of Bmil expression by using short hairpin RNA can inhibit the tumorigenicity and tumor growth of hepatocellular carcinoma cells both in vitro and in vivo. Importantly, Bmil knockdown can block the tumor growth, both in the initiating stages and the fast growing stages. Cellular biology analysis revealed that Bmil knockdown induces cell cycle arrest and apoptosis. Our findings verify Bmil as a qualified treatment target for hepatocellular carcinoma (HCC) and support Bmil targeting treatment with chemotherapeutic agents.
\end{abstract}


Keywords: Bmi1; HCC; knockdown; proliferation; treatment

\section{Introduction}

Hepatocellular carcinoma (HCC) is the third leading cause of death from cancers and the fifth most common malignancy worldwide [1]. HCC is often diagnosed at an advanced stage when it is no longer amenable to curative therapies [2]. Because of the lack of therapeutics, mining the potential therapeutic targets is one of the pivotal missions of fundamental research of liver cancers.

In the past few decades, epidemiologic data have confirmed that chronic viral infections and hepatotoxic agents serve as the major risk factors $[3,4]$, but the molecular pathogenesis of HCC is still largely unknown. It is presumed that the initiation and progression of HCC result from cumulative genetic and epigenetic events, similar to those observed in other solid tumors. The most frequently involved tumor suppressor proteins driving hepatic carcinogenesis are $\mathrm{pRb}, \mathrm{p} 53$, the M6P/IGF2 receptor and E-cadherin [5]. Activation of oncogenes, such as c-Myc, Met and CTNND1, has also been detected in multiple subsets of HCC [6]. Alongside these oncogene alterations, the major pathways implicated in HCC are intensively investigated. These pathways include the RAF/mitogen-activated protein kinase/extracellular signal-regulated kinase (RAF/MEK/ERK) pathway, PI3 kinase/AKT/ mammalian target of rapamycin (PI3K/AKT/mTOR) pathway, canonical WNT/ $\beta$-catenin pathway, insulin-like growth factor pathway, hepatocyte growth factor/c-MET pathway and growth factor-regulated angiogenic signaling pathway [7]. Treatment studies targeting these signaling cascades related to cell survival and proliferation are widely conducted in preclinical and early clinical studies [8].

Besides the oncogenes stated above, Bmil is another critical oncogene that mediates hepatic carcinogenesis [9]. Bmil is a member of the mammalian polycomb group of multimeric transcriptional repressors and is involved in the regulation of development, stem cell self-renewal, cell cycle and senescence [10-13]. Bmil was first identified as an oncogene, because it can cooperate with $c-M y c$ to induce murine B-cell lymphoma [14]. Since then, overexpression of Bmil has been reported in multiple tumor types, including breast cancer [15], colon carcinoma [16], non-small cell lung cancer [17,18], glioblastoma [19], ovarian cancer [20], bladder cancer [21] and nasopharyngeal carcinoma [22]. Similar to many types of solid tumors and leukemia [23], aberrant expression of Bmi1 is also found in human HCC [24,25]. Chiba and colleagues found that Bmil gene is overexpressed in many HCC cell lines, and knockdown of Bmil can reduce the side population in HCC cells [26]. Our previous study also showed that Bmil is overexpressed in almost 1/3 of HCC patients, and Bmi 1 can cooperate with Ras to induce HCC formation in mice [25]. All of these data support that Bmi1 functions as an oncogene in HCC.

As a major member of the PcG family of proteins, Bmil plays important roles during the multiple types of tumorigenesis by epigenetic gene regulation [27]. The molecular mechanisms underlining the functions of Bmil in carcinogenesis have been extensively explored. Several studies have revealed that Bmil mainly promotes tumor development by repressing INK4a/ARF locus, which can induce cell senescence and inhibit the proliferation of cancer cells $[11,13,18]$. In HCC, however, Bmil was shown to drive HCC pathogenesis independent of repressing INK4a/ARF [24,25]. In addition, the cellular 
mechanism of how Bmil induces HCC and maintains HCC growth is not fully understood. In our past study, no senescence was observed upon Bmil repression in HCC [25]. Hence, the exact mechanisms of Bmil in HCC carcinogenesis are still elusive.

To validate the feasibility of using Bmil as a potential target for HCC treatment, here, we report that knockdown of Bmil gene inhibits $\mathrm{HCC}$ cell proliferation in vitro and in vivo, both in the onset periods and the fast growing periods of the neoplasm. The cellular mechanism study revealed that Bmil knockdown inhibits HCC cell growth by inducing both cell cycle arrest and apoptosis.

\section{Results and Discussion}

\subsection{Bmi1 Knockdown Inhibits the Growth of Hep3B Cells by Inducing Cell Cycle Arrest}

To explore the effects of Bmil repression on $\mathrm{HCC}$ growth, we first checked the impact of Bmil knockdown $(\mathrm{KO})$ on HCC cells in vitro. Hep3B cells transfected with Bmil shRNA lentivirus or control vector lentivirus were selected by $1 \mu \mathrm{g} / \mathrm{mL}$ of puromycin. Then, the Bmil expression and the proliferation of Hep3B cells were examined. Western blotting showed that the expression of Bmi1 was significantly inhibited in Bmil KO Hep3B cells (Figure 1A). Quantitative RT-PCR also showed that the Bmil mRNA level decreased to 0.12-fold in Bmil KO Hep3B cells (Figure 1B). The phenotypic observation that plenty of Bmil KO cells were detached from the culture dish indicated obvious apoptosis or cell death (Figure 1C). Growth curve analysis showed that the growth of Hep3B cells was significantly impaired upon Bmil knockdown (Figure 1C). Reduced BrdU staining in Bmil KO Hep3B cells confirmed the inhibited proliferation of Bmil KO Hep3B cells (Figure 1D). These results clearly indicated that the Bmil KO significantly inhibited the growth of HCC cells.

Figure 1. Knocking down Bmil inhibits the proliferation of Hep3B cells in vitro. Western blotting, proliferation and BrdU incorporation assays were done by using the Hep3B cells after lentivirus infection and puromycin selection for three days. (A) Western blotting detection of Bmil expression. Tubulin was used as a loading control; (B) Real-time qRT-PCR detection of mRNA level of Bmil $(n=3)$; (C) Cellular morphology of Bmi1 knockdown Hep3B cells. Cells were plated in six-well plates for $1 \times 10^{5}$ cells per well and observed at three time points. Cells were counted after trypan blue staining by using a blood counting chamber ( $n=3$ wells); and (D) Proliferation detection of cells by the BrdU incorporation assay. The nucleus was stained blue by DAPI (4',6-diamidino-2-phenylindole), and BrdU stained red. The percentage of BrdU-positive cells was determined by counting BrdU-positive cells and total cells in the same fields $(n=3)$. Data are expressed as the mean $\pm \mathrm{SD}$ (standard deviation). $* p<0.05$, and $* * p<0.01$.
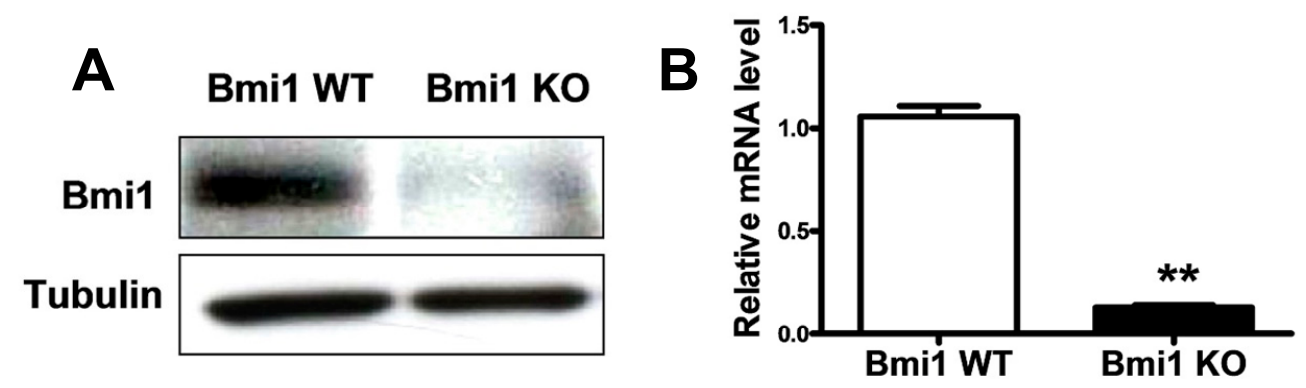
Figure 1. Cont.

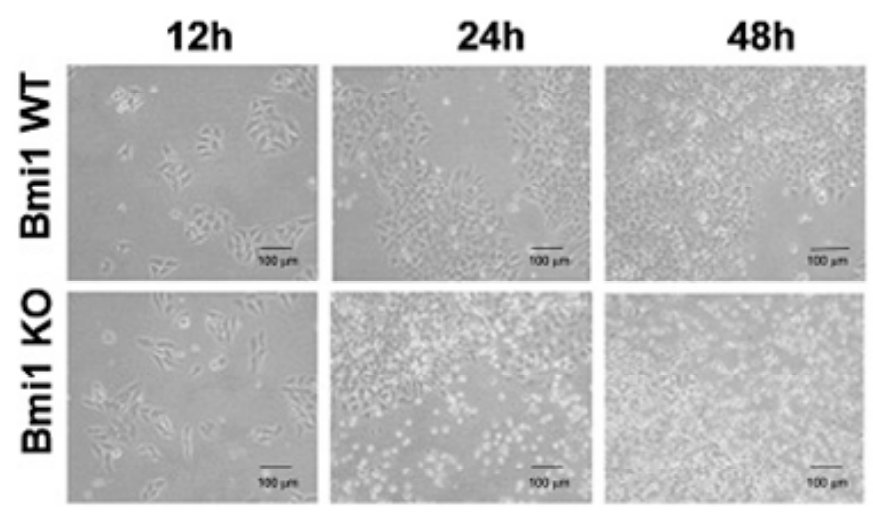

(C)
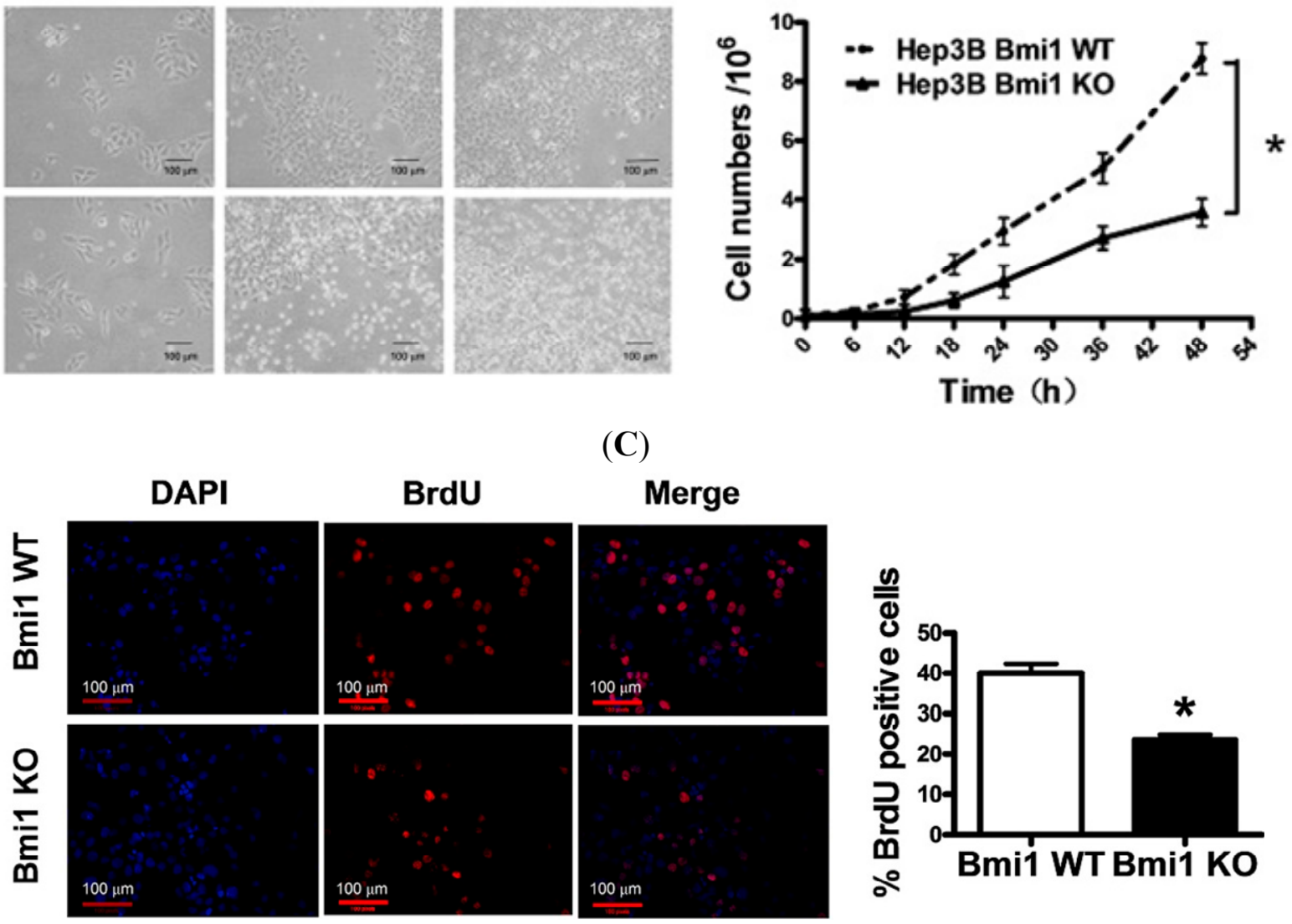

Merge
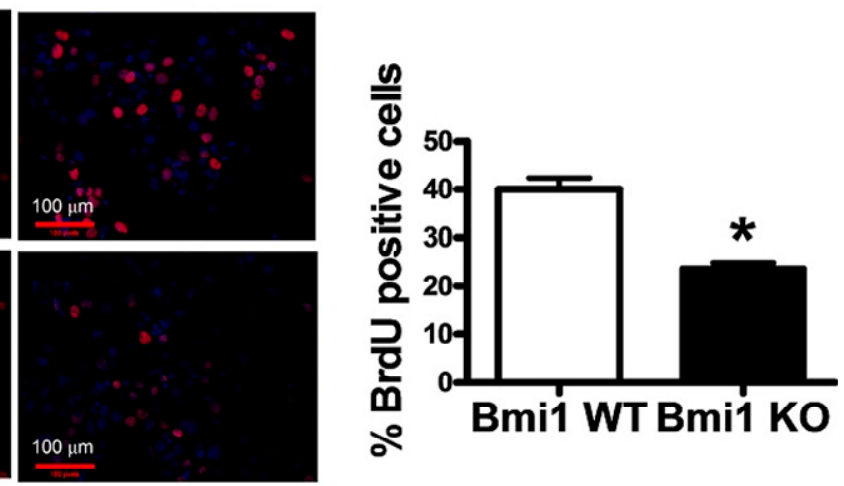

(D)

We further explored the cellular mechanism of Hep3B cell growth inhibition by Bmi1 knockout. We first performed the TdT-mediated dUTP nick end labeling (TUNEL) assay and found no significantly increased apoptosis in Bmil KO Hep3B cells (Figure 2A). Then, we conducted cell cycle analysis through both immunostaining and fluorescence-activated cell sorting (FACS). Immunofluorescence staining showed that the cyclin D1 expression was blocked in some Bmil KO Hep3B cells (Figure 2B). Cell cycle analysis by FACS showed that Bmi1 KO Hep3B cells were accumulated in the G1 phase, suggesting a G1 phase arrest in Bmil KO cells (Figure 2C). These data collectively suggest that the Bmil KO inhibits HCC cell growth mainly by inducing cell cycle arrest. Western blot results showed that expression of cell cycle protein cyclin D1 and cyclin E were downregulated, whereas the expression of apoptosis-associated proteins Bcl-2, Bax and caspase-3 showed no significant changes (Figure 2D). These results suggest that Bmil KO in Hep3B cells induced cell cycle arrest in the G1 phase, but did not induce apoptosis in vitro. 
Figure 2. Bmil downregulation inhibits Hep3B cell growth by inducing cell cycle arrest. Hep3B cells were infected with Bmil shRNA lentivirus and were selected by puromycin. Then, $1 \times 10^{5}$ Hep3B cells were seeded in six-well plates with a cover slip. After $48 \mathrm{~h}$, the cells were processed for western blot, immunofluorescence staining and FACS assays. (A) Apoptotic detection by TUNEL assay $(100 \times)$. The nucleus was stained with blue DAPI, and TUNEL is shown as green; (B) The immunofluorescence staining of cell cycle protein cyclin D1 $(400 \times)$. The nucleus was stained with blue DAPI, and cyline D1 was stained red. Quantitative analyses were conducted by counting staining positive cells and total cells in the same fields ( $n=3$ fields); (C) Cell cycle analysis by FACS. For FACS detection, $2 \times 10^{5}$ cells were seeded in six-well plates and cultured for $24 \mathrm{~h}$. A total of $5 \times 10^{4}$ cells were detected for each sample; and (D) Western blotting detection of apoptosis and cell cycle-associated proteins. Data are expressed as the mean \pm SD. ${ }^{*} p<0.05$.

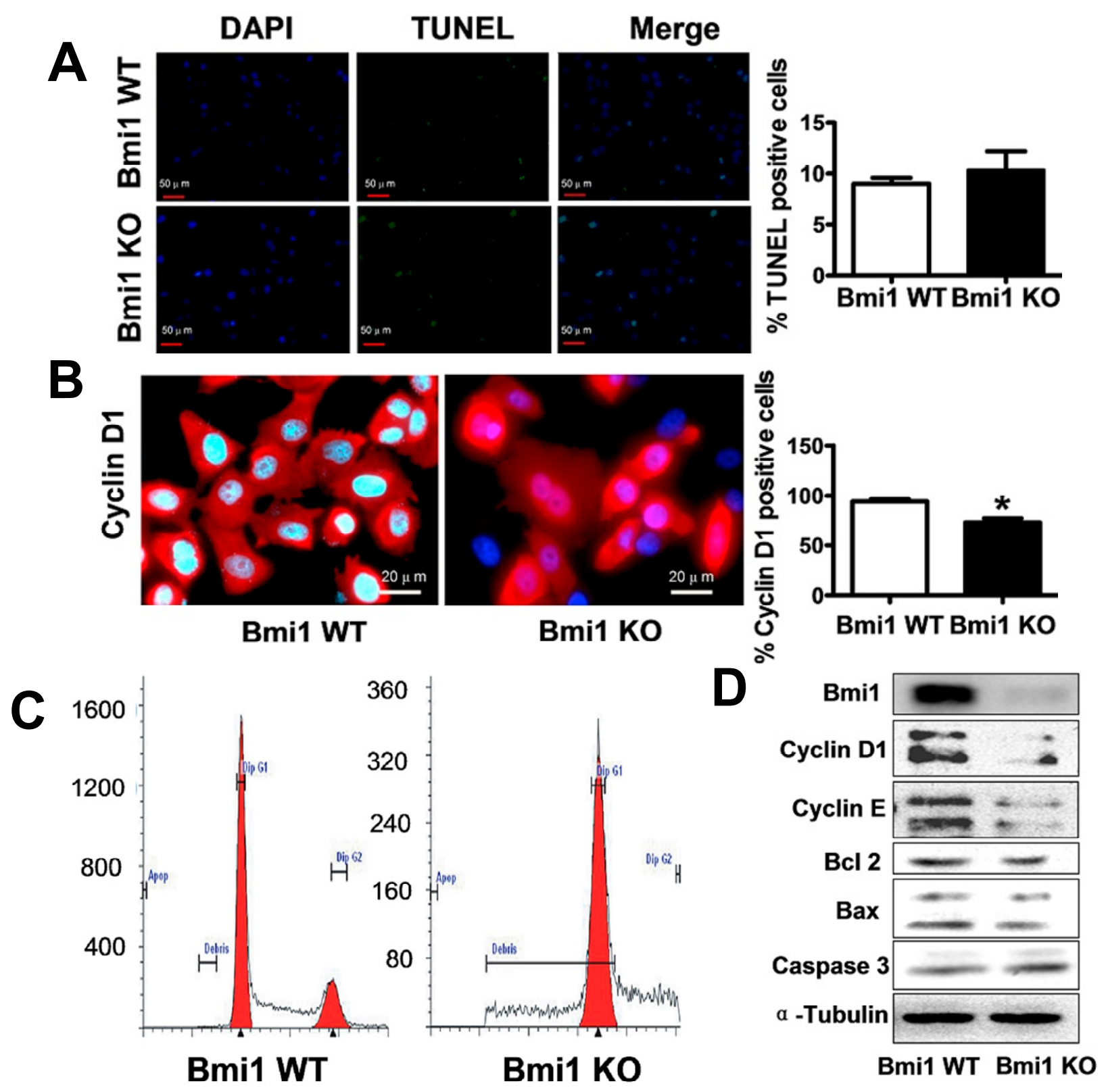




\subsection{Bmil Knockdown Impairs the Tumor Formation Ability of HCC Cells in Nude Mice}

To determine the effects of Bmi1 KO on HCC growth in vivo, we first checked the impact of Bmil $\mathrm{KO}$ on the tumorigenicity of Hep3B. The colony formation assay showed that Bmi1 KO impaired the colony formation ability of Hep3B cells significantly. Both the colony numbers and sizes of Bmi1 KO Hep3B cells were significantly lower than those of WT (wild type) Hep3B cells (Figure 3A). To assay the tumorigenicity of Bmil KO Hep3B cells in mice, both Bmil WT and KO Hep3B cells were inoculated into the BALB/c nude mice with three different cell numbers, $2 \times 10^{6}, 4 \times 10^{6}$ and $6 \times 10^{6}$ cells $(n=10)$. We found that when $6 \times 10^{6}$ cells were injected, both the WT and Bmil KO Hep3B cells could form tumors in the nude mice. When the cell number reduced to $4 \times 10^{6}$, most of the WT cell-injected mice (9/10) formed tumors, whereas less than half of the Bmil KO cell-injected mice (4/10) formed tumors. When the cell numbers reduced to $2 \times 10^{6}$, Bmil KO Hep3B cells failed to initiate subcutaneous tumors in any recipient mice. However, WT Hep3B cells still formed tumors in three of 10 injected mice (Figure 3B). For the tumors derived from $6 \times 10^{6}$ cell injection, growth curve showed that the tumor formation from the Bmil KO cells was significantly delayed compared to the WT cells, and Bmil KO significantly repressed tumor growth (Figure 3C). In addition, the sizes of Bmil KO tumors were much smaller than those of WT tumors (Figure 3D). The Bmil expression in the Bmil KO tumors was confirmed by western blotting and showed that the Bmil shRNA lentivirus can constantly inhibit the expression of Bmil for at least 20 days (Figure 3E). These results collectively illustrate that the tumor-initiating capacity of Hep3B cells is profoundly impaired by Bmil knockdown.

Figure 3. Bmil knockdown impairs the tumor formation ability of Hep3B cells in nude mice. (A) Colony formation assay of Bmil knockdown Hep3B cells. One thousand Hep3B cells were seeded in six-well plates and cultured for three days. For the quantitative analysis, three wells of colonies were counted; (B) The tumor-initiating ability of Hep3B cells in nude mice. The tumor formation was observed for two weeks after inoculation ( $n=10$ mice/group); (C) Growth curves of the tumors formed by Bmil WT and KO Hep3B cell injection. Bmil WT or KO Hep3B cells $\left(6 \times 10^{6}\right)$ were injected into nude mice subcutaneously, and the tumor volumes were measured every other day; (D) The tumors formed in recipient mice by injecting $6 \times 10^{6} \mathrm{Bmil} \mathrm{KO}$ or WT Hep3B cells. The red arrows in each image are used to indicate the tumors; and (E) Bmil expression detection by western blotting in the formed tumors. Data are expressed as the mean \pm SD. ${ }^{*} p<0.05$, and $* * p<0.01$.

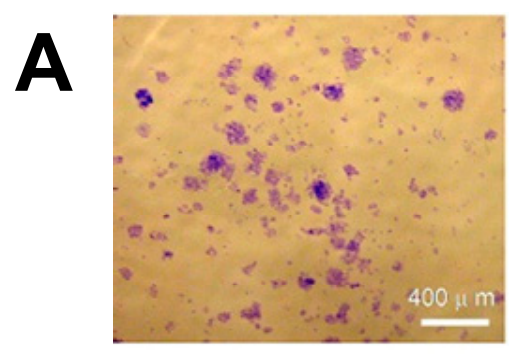

Bmi1 WT

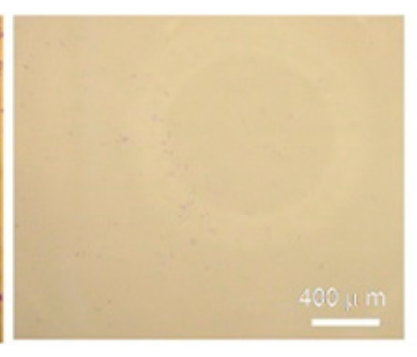

Bmi1 KO

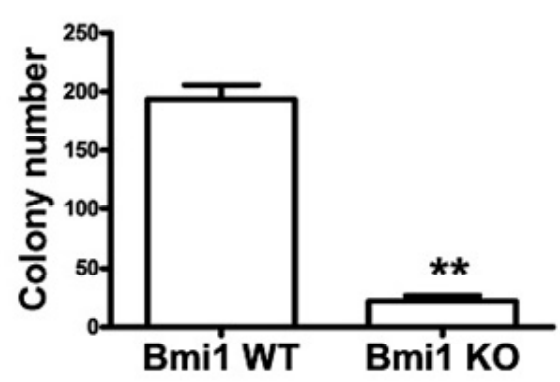


Figure 3. Cont.

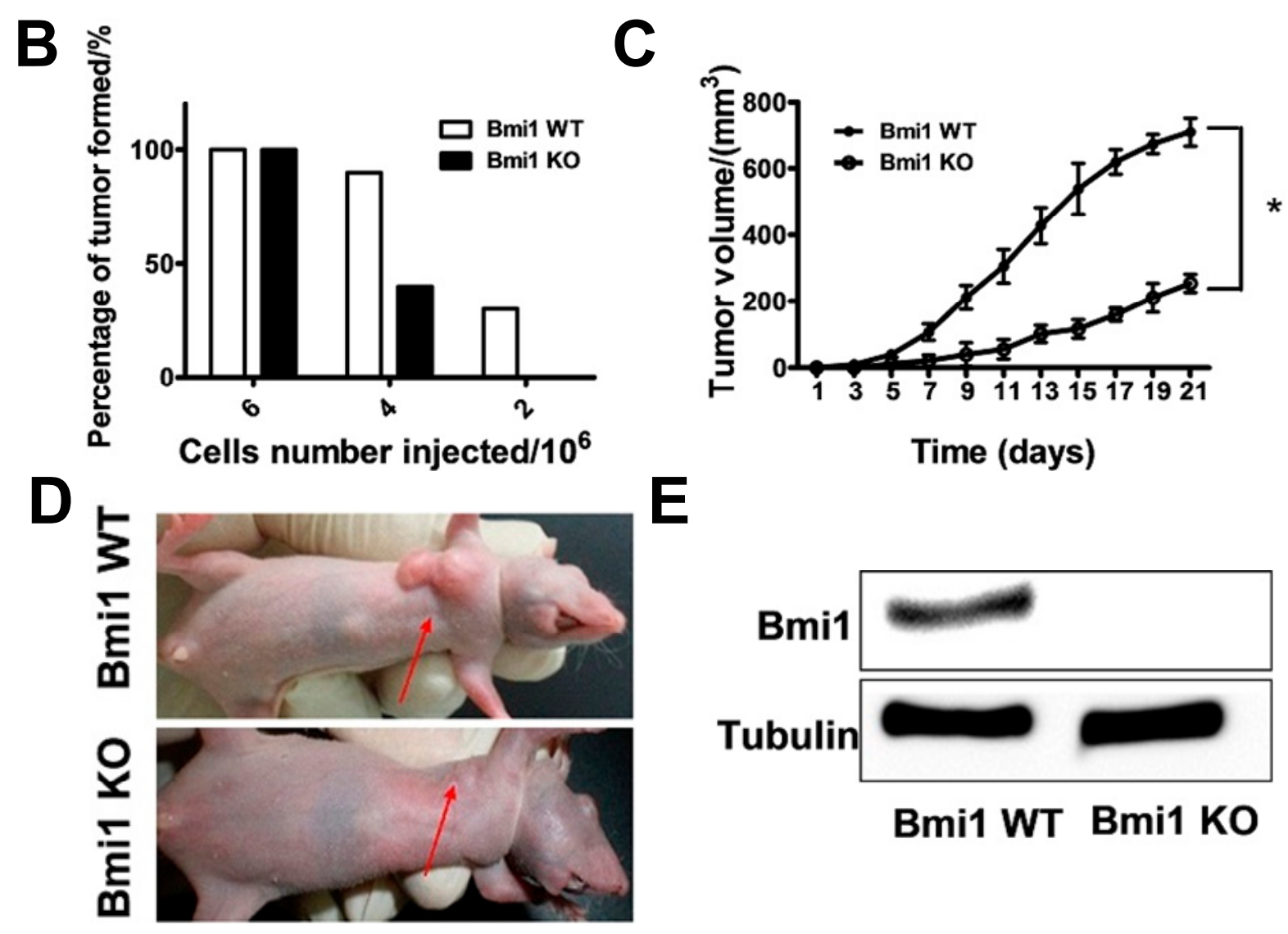

\subsection{Conditional Knockdown of Bmil by Doxycycline Inhibits the HCC Cell Growth in Vitro}

Although knockdown of Bmil significantly impaired the tumorigenicity of HCC cells in vitro and in nude mice, the effect of Bmil knockout on HCC growth in vivo was still unclear. Clinically, treatments only happen after cancer diagnosis, rather than ahead of the tumor formation. Thus, we further asked whether knockdown of Bmil can block the growth of HCC in the fast growing stages, at which most cancer patients are diagnosed. To address this question, we cloned the Bmil shRNA to an inducible lentivirus expression vector, pLKO-Tet-On plasmid, and prepared the Bmi1/pLKO-Tet-On lentivirus. In these infected cells, doxycycline can trigger the Bmil shRNA expression and then silence the Bmil expression. The results showed that treatment with $0.1 \mu \mathrm{g} / \mathrm{mL}$ of doxycycline for $24 \mathrm{~h}$ significantly inhibited Bmi1 expression in Hep3B and Huh7 cells transfected with Bmi1/pLKO-Tet-On lentivirus (Figure 4A). Quantitative RT-PCR showed that Bmil expression was reduced to 30\% and 20\%, respectively, in Huh7 and Hep3B cells by doxycycline treatment (Figure 4B). Growth curve analysis showed that the proliferation of Huh7 and Hep3B cells was significantly inhibited upon Bmil knockdown (Figure 4C). The dose escalation efficacy assay by treating the cells with various concentration of doxycycline showed that doxycycline treatment inhibits the growth of Hep3B and Huh7 cells in a dose-dependent manner. A higher concentration $(0.01 v s .0 .1 \mu \mathrm{g} / \mathrm{mL})$ of doxycycline resulted in stronger blocking effects $60 \%$ inhibition $v s .40 \%$ inhibition), and treatments for a longer time enhanced the effects, as well (Figure 4D). These results suggest that Bmi1 KO by doxycycline inhibits the cell growth in a dose-dependent manner in vitro. 
Figure 4. Conditional knockdown of Bmil by the tet-on system inhibits the HCC cell growth in vitro. Hep3B and Huh7 cells were infected with lentivirus carrying inducible Bmi1 shRNA. After $48 \mathrm{~h}$ of puromycin selection, $0.1 \mu \mathrm{g} / \mathrm{mL}$ of doxycycline was added in the culture medium to activate the Bmil shRNA expression. After $48 \mathrm{~h}$ of doxycycline treatment, the cells were processed for western blot, qRT-PCR and proliferation assays. (A) Western blotting of Bmil in the Hep3B and Huh7 cells transfected with Bmil shRNA lentivirus. Hep3B and Huh7 cells were infected with lentivirus carrying inducible Bmi1 shRNA, and $0.1 \mu \mathrm{g} / \mathrm{mL}$ of doxycycline were added in the culture medium to activate the Bmil shRNA expression; (B) qRT-PCR results of the Bmil mRNA level in Huh7 and Hep3B cells transfected with Bmil shRNA by pLKO-Tet-On lentivirus; (C) The growth curves of Huh7 and Hep3B cells when the Bmil gene was knocked down. Cells were cultured in medium with $0.1 \mu \mathrm{g} / \mathrm{mL}$ of doxycycline after infecting with lentivirus, and cell numbers were counted at different time points after trypsin digestion; and (D) Cell growth of Huh7 and Hep3B cells treated with different concentrations of doxycycline. The morphology of Hep3B cells treated with doxycycline is shown on the left. The Huh7 and Hep3B cell numbers were counted after $1 \times 10^{5}$ cells were cultured in six-well plates for 48 h. Data are expressed as the mean \pm SD. * $p<0.05$, and $* * p<0.01$.

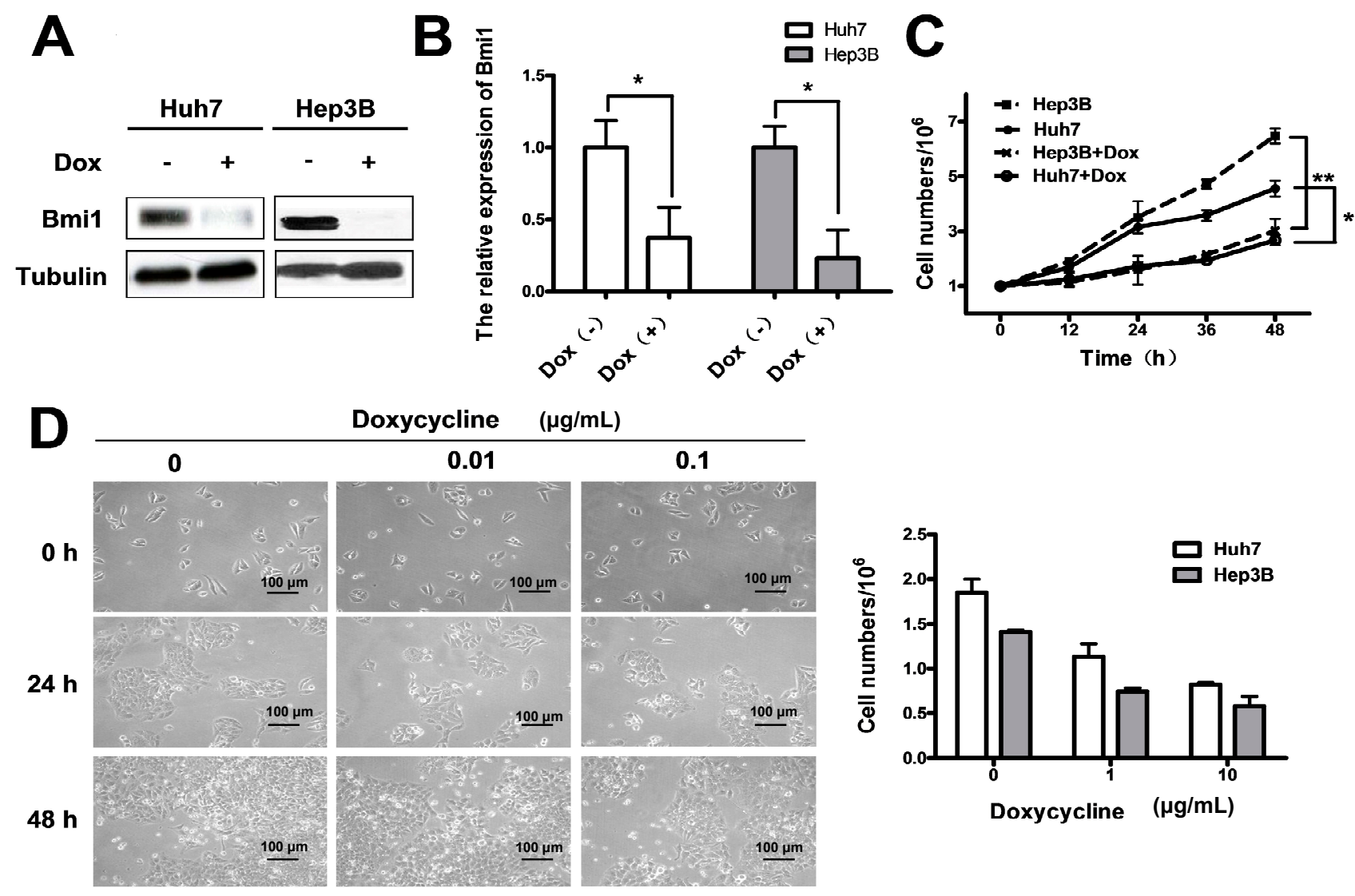

\subsection{Shutdown of Bmil Represses the Tumor Growth in the Fast Growing Period in Nude Mice}

To determine whether the knockdown of Bmil can inhibit the tumor growth in fast growing periods in vivo, Hep3B cells transfected with Bmil/pLKO-Tet-On were implanted in nude mice to generate the tumor bearing mice. When the tumors grew to $\sim 100 \mathrm{~mm}^{3}$, autoclaved water with $1.5 \mathrm{mg} / \mathrm{mL}$ of 
doxycycline was given to the treatment group mice and regular autoclaved water was continued for control group mice. Ten days after doxycycline treatment, the tumors of treated mice were markedly smaller in comparison with the control group mice (Figure 5A,B). When the tumors of control mice grew to $\sim 200 \mathrm{~mm}^{3}$, the tumors of treated mice were only $\sim 100 \mathrm{~mm}^{3}$ (Figure 5A,B). The growth curves also showed that Bmi1 KO Hep3B tumors maintained their sizes during the treatments for 10 days, while tumors of the untreated mice kept growing quickly (Figure 5A). Correspondingly, the doxycycline treatment also promoted the survival of tumor-bearing mice. The median survival time of the treated mice was 24 days after tumor formation $\left(100 \mathrm{~mm}^{3}\right)$, while for the untreated mice, it was 16 days (Figure 5C). Western blotting of the tumor samples showed that the expression of cyclin D1 and E was decreased, whereas the expression of Bax and caspase-3 was increased (Figure 5D). This clearly indicated that Bmil knockdown resulted in cell cycle arrest and apoptosis. Taken together, these data showed that knockdown of Bmil expression can inhibit the growth of $\mathrm{HCC}$ in fast growing periods in vivo.

Figure 5. Shutdown of Bmil represses the growth of the fast growing tumor in nude mice. (A) The growth of tumors in mice with or without doxycycline for 10 days. For the xenograft tumor model, $6 \times 10^{6} \mathrm{Hep} 3 \mathrm{~B}$ cells transfected with pLK-Tet-on-Bmil lentivirus were injected per nude mouse. The tumor volume was measured every other day. The treatment group was supplied with $1.5 \mathrm{mg} / \mathrm{mL}$ of doxycycline in the drinking water from the sixth day, when the tumors grew to $\sim 100 \mathrm{~mm}^{3}$, whereas the control group was supplied still with regular autoclaved water. The pink arrow indicates that the treatment group begun to be supplied with doxycycline (DOX) in the drinking water; (B) The doxycycline-treated mice had smaller-sized tumors compared with control group mice. The pictures were taken on the sixth day after doxycycline treatment. The red arrows in each image are used to indicate the tumors; $(\mathbf{C})$ The survival curve of tumor-bearing mice. The survival of mice was recorded since the mice were treated with doxycycline. Moribund mice or mice with a tumor $>1000 \mathrm{~mm}^{3}$ were recorded as dead; and (D) Western blotting of Bmi1, apoptosis and cell cycle-associated proteins in the tumor tissues. After the mice were sacrificed, the tumors were collected for western blotting. Data are expressed as the mean \pm SD. ${ }^{*} p<0.05$.

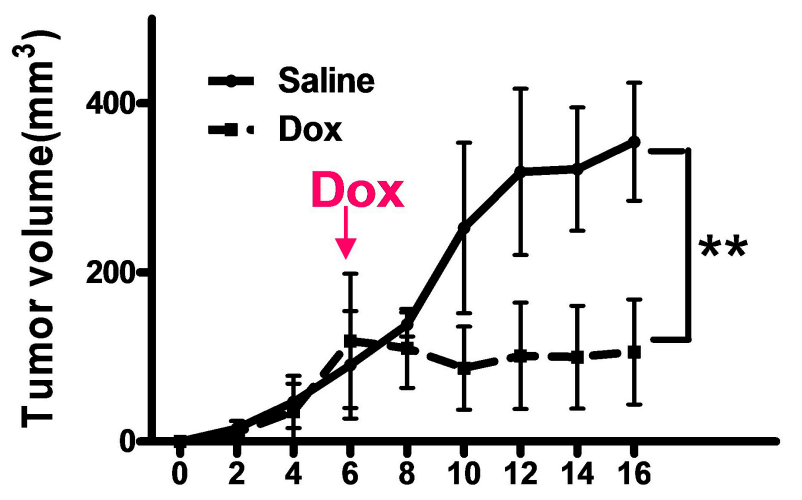

(A)

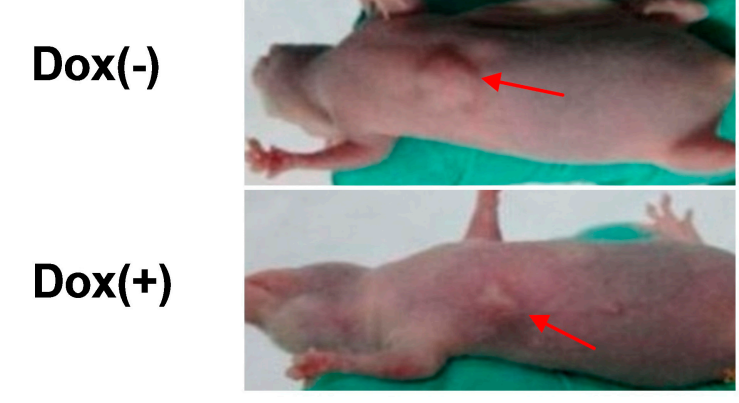

(B) 
Figure 5. Cont.

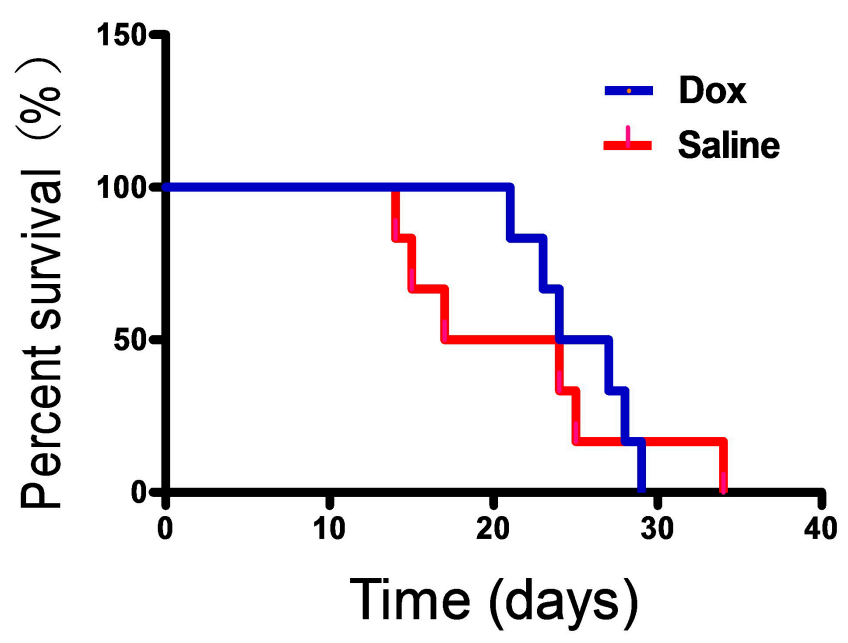

(C)

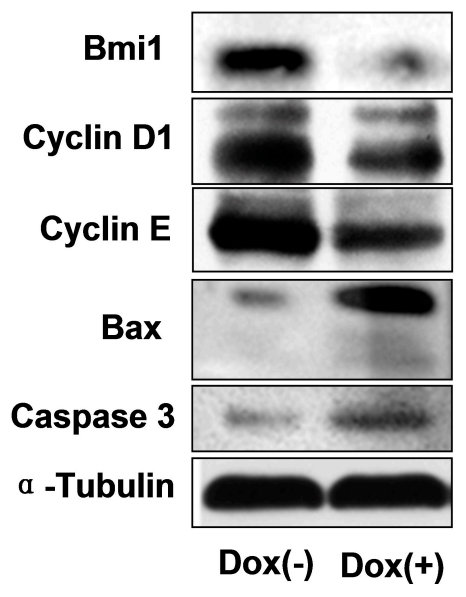

(D)

To further ensure that the tumor growth arrest resulted from the Bmil knockdown, three moribund mice of each group were sacrificed for immunoblotting and immunohistochemistry after 10 days of doxycycline or regular water treatment. Histologic examination showed that the untreated tumors consisted of frequent trabecular disorganization and exhibited clearly the nuclear expression of Bmil (Figure 6A). The Bmil staining showed significantly abrogated Bmil expression in the doxycycline-treated mice (Figure 6A). Ki67 staining revealed a high level proliferation for WT Hep3B tumors and a relatively low level proliferation of Bmil KO tumors (Figure 6A). The TUNEL assay showed that Bmil knockdown by doxycycline generated increased apoptotic signals in the treated Hep3B tumor samples (Figure 6B). Combined with the in vitro study, these results suggest that the Bmil knockdown can inhibit the HCC growth in mice, and the mechanism is mainly due to the induction of cell cycle arrest, while increased apoptosis was observed in tumor tissues.

Figure 6. Characterization and apoptosis detection of tumor tissues. (A) Immunohistology of tumor tissues in nude mice. Tumor tissues were collected from the moribund mice at the end of the experiment; and (B) TUNEL assay in the tumors treated with doxycycline. The percentage of TUNEL-positive cells was determined by counting TUNEL-positive cells and total cells in the same fields $(n=3)$. Data are expressed as the mean $\pm \mathrm{SD}$. $* p<0.05$.

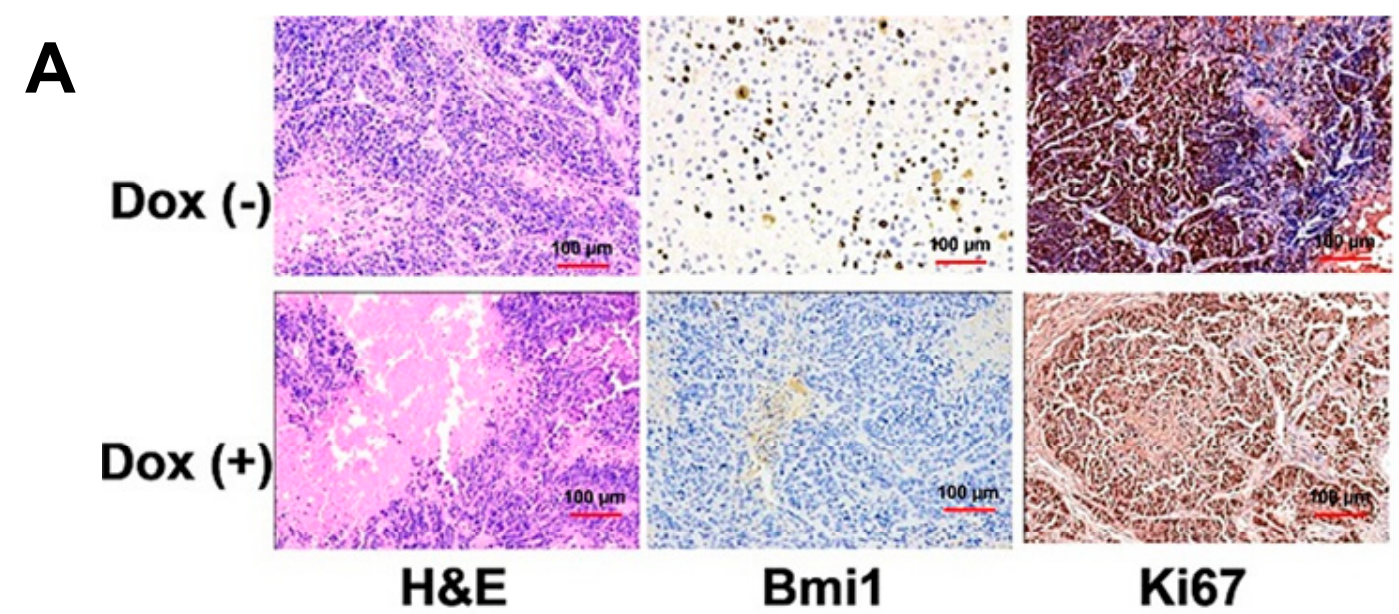


Figure 6. Cont.

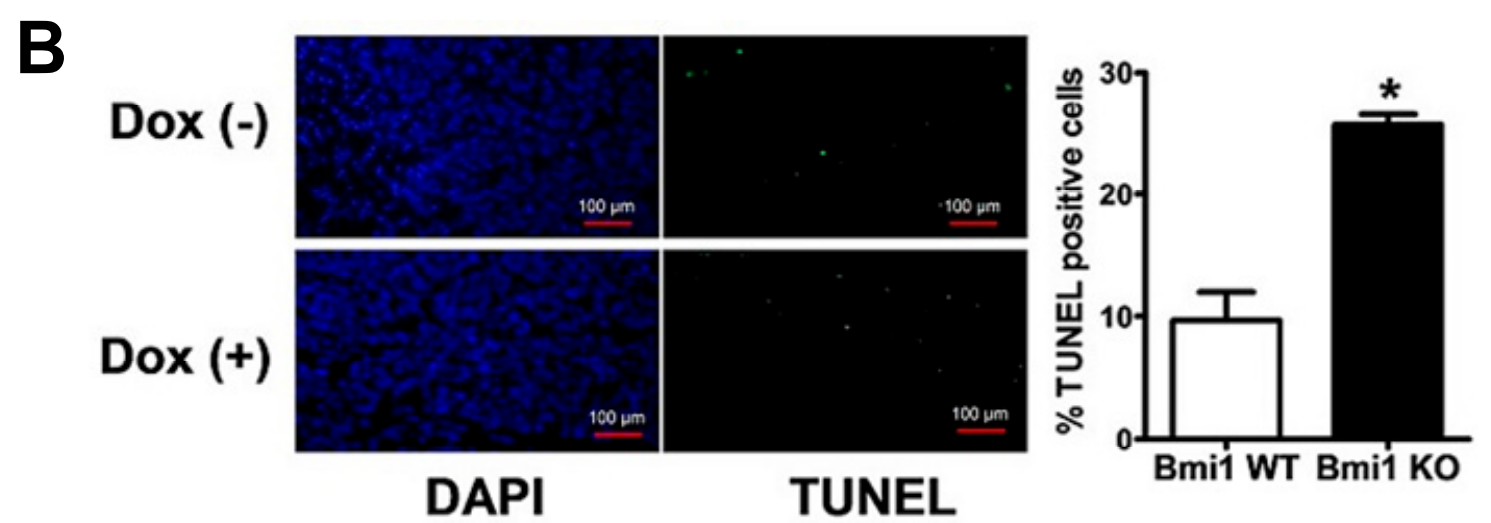

\subsection{Discussion}

Human HCC is one of the most frequent solid tumors, ranking fifth in incidence and third in mortality worldwide. Screening and validation of the potential therapeutic targets for HCC have long been the mission of fundamental studies. The Bmil gene has been recognized as an oncogene in HCC and many other types of tumors [18,28-30]. Using Bmil transgenic or knockout mice, several research groups have showed that Bmil expression is required for the tumorigenesis of $\mathrm{HCC}$ [25,31]. Although some studies showed that repression of Bmil can inhibit the growth of $\mathrm{HCC}$ cells in vitro, more in vivo evidence was needed to validate Bmil as a therapeutic target for HCC treatment, especially in the late stages. In our present study, we showed that Bmil knockdown can inhibit HCC cell growth in vivo, both in the initiating stages and progressing stages. Especially, our data indicated that even in the fast growing stages of HCC, repression of Bmil can still block the growth of HCC. Our study therefore provides pivotal evidence to support Bmil as a target for HCC treatment.

Such kinds of studies have been done by other groups. Similarly, all of the results support Bmil as a potential therapeutic target. Ruan et al. showed that Bmil downregulation inhibits HCC cell growth and tumorsphere formation in vitro, blocks cell cycle transition from the G0/G1 to the S phase of HCC cell lines, inhibits tumorigenicity in vivo and enhances HCC sensitivity to sorafenib [32]. The results of Zhang et al. indicate that the downregulation of the Bmil gene by RNAi can inhibit the proliferation and invasiveness of HCC cells and increases their sensitivity to 5-FU treatment [33]. Wu and colleagues reported that repression of Bmil can enhance the sensitivity of osteosarcoma to cisplatin [34]. Wang et al. reported that knockdown of Bmil also reduces the resistance of ovarian cancer cells to cisplatin [20]. All of these studies imply that the Bmil is a potential target for cancer treatments, including $\mathrm{HCC}$.

Although some of these studies used a mouse model to show the efficacy of Bmil knockdown on tumor growth inhibition, they failed to provide evidence that repression of Bmil in the fast growing stages will be effective. By using a conditional knockdown system, we, for the first time, showed that knockdown of Bmil in the fast growing stages, instead of from the onset of tumors, can still inhibit the growth of HCC in a mouse model. Though the xenograft mouse model has many deficiencies, it is still a well-accepted mouse model to evaluate the efficacy of anti-tumor drugs or treatments. However, we are currently evaluating the possibility of using a hydrodynamic injection tumor model for the further evaluation of oncogene targeting treatments. 
Yonemitsu et al. reported that Bmil was overexpressed in 52 tumor tissues $(60.5 \%)$ of 86 hepatocellular carcinoma surgical specimens, and the cumulative recurrence rate was significantly higher in patients positive for Bmil $(p=0.039)$ than in their negative counterparts, as determined by Kaplan-Meier analysis [8]. These data indicate that Bmil is associated with the malignant progression of HCC. Our data showed that knockdown of Bmil can prolong the survival of tumor-bearing mice from 16 to 24 days, and it seems that eight days is not significant compared to the average life span of nude mice of about 120 days. However, the only approved drug on the market for HCC treatment, sorafenib, can only prolong the median survival time of HCC patients for an average of 3.4 month [9]. Considering that the average life span of a human is about 70 years, an eight-day expansion of the life span for nude mice was a significant improvement, and this equals 56 months for humans. In addition, our other study has shown that co-delivery of Bmil siRNA and doxorubicin can significantly prolong the survival of tumor-bearing mice [10], which hints at its possible application together with chemotherapy. Considering the urgent demand for the effective treatment of HCC, the Bmil targeting treatment holds promise as one of the future therapeutic options.

Several studies have revealed that Bmil maintains tumor growth by inhibiting apoptosis, and knockout of Bmil will result in the apoptosis of cancer cells [20,35]. In our study, we observed apoptosis in the xenograft tumors when Bmil was knocked down. However, we did not observe the increased apoptosis in the cultured Bmil KO Hep3B cells. This is possibly due to the different growing conditions for cultured HCC cells. In cell culture, apoptotic HCC cells will quickly be detached from the culture dish, which makes them difficult to detect. In tumor tissues, however, the tumor microenvironment will help maintain the survival of the apoptotic HCC cells, and thus, apoptotic HCC cells are easier to be detected by TUNEL staining.

Bmil exerts its oncogenic function in many types of cancers by silencing the INK4a/ARF (Cdkn2a) tumor suppressor locus encoding the p16 (INK4a) and p14 (ARF) proteins. The p16 inhibits cell cycle progression by disrupting the cyclin D/CDK 4/6 complex, whereas p14 suppresses Mdm2 function and subsequently results in p53 stabilization and subsequent apoptosis. Thus, the tumor-promoting function of the Bmil gene has contributed to the inhibition of cell apoptosis [35]. However, emerging evidence indicates that Bmil also functions in an INK4a/ARF independent manner [19,24,25,36,37] or partially dependent manner [18,38] in the tumorigenic context. Our previous study revealed that knockdown of Bmil does not increase the mRNA and protein level of p14 and p16 in Huh7, Hep3B and SK-Hep1 cell lines [25]. However, how the Bmil KO induced cell cycle arrest was still unresolved. Clearly, the next step in the characterization of molecular mechanisms of Bmil is to identify novel targets and/or pathways regulated by Bmil during HCC pathogenesis and maintenance.

\section{Experimental Section}

\subsection{Cell Culture, Short Hairpin RNA Constructs, Lentivirus and Infection}

The Huh7 and Hep3B cell lines are from the American Type Culture Collection (ATCC, Manassas, VA, USA). Cells were cultured in Dulbecco's Modified Eagle's Medium (Hyclone, Logan, UT, USA) containing 10\% fetal bovine serum (Gibco, Gaithersburg, MD, USA), $100 \mathrm{U} / \mathrm{mL}$ penicillin (Sigma-Aldrich, St. Louis, MO, USA) and $100 \mathrm{mg} / \mathrm{mL}$ streptomycin (Sigma-Aldrich) in $37{ }^{\circ} \mathrm{C}$ and $5 \%$ 
$\mathrm{CO}_{2}$ incubators. M-plasmocin (Invivogen, San Diego, CA, USA) at a concentration of $2.5 \mu \mathrm{g} / \mathrm{mL}$ was used to prevent possible mycoplasma infection.

ShRNA constructs Bmil/pLKO.1 (TRCN0000020155, NM_005180.5-693s1c1) used to silence Bmil expression were obtained from OpenBiosystems (GE healthcare, New York, NY, USA). Control pLKO.1 (empty vector) or SC/PLKO.1 (with a scrambled sequence) plasmids were obtained from Addgene (Addgene, Madison, MD, USA). The doxycycline inducible Bmil shRNA vector was obtained by cloning the Bmil shRNA (5'-CCGGCCAGACCACTACTGAATATAACTCGAGTTAT ATTCAGTAGTGGTCTGGTTTTT-3' and 5'-AATTAAAAACCAGACCACTACTGAATATAACTC GAGTTATATTCAGTAGTGGTCTGG-3') into the AgeI/EcoRI sites of the pLKO-Tet-On vector downstream of the U6 promoter. Then, the vectors were packaged by lentivirus. Lentivirus generated by the biotechnology company (Neuron Biotech, Shanghai, China) was used to infect HCC cells by adding the thawed virus into the cell culture directly. Two days after infection, cells were expanded and selected with $1 \mu \mathrm{g} / \mathrm{mL}$ puromycin for 2 days and harvested for protein or RNA analysis.

\subsection{RNA Extraction and Real-Time $q P C R$}

Total RNA was extracted using the RNeasy Mini kit (Qiagen, Hilden, Germany). Total RNA of $5 \mu \mathrm{g}$ was used to synthesize the first strand of cDNA by using SuperScript II RT $200 \mathrm{U} / \mathrm{mL}$ (Invitrogen, Carlsbad, CA, USA). The Bmil mRNA level was evaluated by real-time PCR on an ABI Prism H7300 (Applied Biosystems, Foster City, CA, USA) with SYBR Green PCR core reagents. The rRNA was applied as the input reference. The primers used in this study are listed below: Bmil: F, 5'-TGGACTGACAAATGCTGGAGA-3', R, 5'-GAAGATTGGTGGTGGTTACCGCTG-3'; rRNA: F, 5'-CGGCTACCACATCCAAGGAA-3', R, 5'-GCTGGAATTACCGCGGCT-3'.

\subsection{Protein Lysates and Western Blotting}

Protein extracts of cell lines or tissues were prepared by using M-PER mammalian protein extraction reagent (Thermo Fisher, Rockford, IL, USA) plus proteinase inhibitor cocktail (Roche, Indianapolis, IN, USA). Protein concentrations of the lysate were quantified using the BCA protein assay (Beyotime, Beijing, China). Western blotting was done as described elsewhere [39]. Antibodies were prepared as follows: Anti-Bmi1 1:1000 (Millipore, Bedford, MA, USA), anti-cyclin D1 1:1000 (Milipore, Bedford, MA, USA), anti-cyclin E 1:1000 (Abcam, San Francisco, CA, USA), anti-Bcl2 1:1000 (Abcam), anti-Bax 1:1000 (Abcam), anti-caspase 3 1:1000 (Abcam) and anti- $\alpha$-tubulin 1:1000 (Boster, Wuhan, China).

\subsection{Cell Proliferation and Cell Cycle Assays}

To assay the cell proliferation rate, an equal number of cells was seeded in 6-well plates. After growth, cells were digested by trypsin (Beyotime, Beijing, China) and stained by trypan blue (Beyotime, Beijing, China) at different time points. Then, the cells were counted by a blood counting chamber, and only viable cells were counted. For cell cycle analysis, cells were digested by trypsin and collected with the suspension cells together. After fixation by $70 \%$ ethanol, cells were incubated by $0.5 \mathrm{mg} / \mathrm{mL}$ RNase and $0.025 \mathrm{mg} / \mathrm{mL}$ propidium iodide for $30 \mathrm{~min}$. For each sample, $5 \times 10^{4}$ cells were 
detected by flow cytometry (CytomicsTM FC 500, Beckman Coulter, CA, USA), and the results were analyzed by using software FlowJo 7.6 (FlowJo, Ashland, OR, USA). BrdU labeling was performed as described in the literature [40].

\subsection{Analysis of Clonogenicity in Vitro}

For colony formation analysis, Hep3B cells were infected by lentivirus for $48 \mathrm{~h}$ and then selected by $1 \mu \mathrm{g} / \mathrm{mL}$ puromycin for $48 \mathrm{~h}$. Then, 1000 viable Hep3B cells were plated in 6 -well plates and maintained in complete DMEM medium for 1 week. Colonies were fixed with methanol and stained with $0.1 \%$ crystal violet in $20 \%$ methanol. Triplicate wells were prepared for each transfectant, and the experiment was repeated twice.

\subsection{Mice and Xenograft Mouse Model}

Female BALB/c nude mice (6-8 weeks of age, 16-18 g) were obtained from Huafukang Technology Corporation (Beijing, China), kept in filter-topped cages with standard rodent chow and had water available ad libitum and a $12 \mathrm{~h}$ light/dark cycle. The experiments were performed according to national regulations and approved by the Animal Experiments Ethical Committee of Huazhong University of Science and Technology. Hep3B cells infected with lentivirus were selected by puromycin and then expanded. For the subcutaneous implantation, $2 \times 10^{6}, 4 \times 10^{6}$ or $6 \times 10^{6}$ Hep3B cells were injected per nude mouse. After the implantation, tumor growth was observed every other day, and tumor volumes were calculated as $V=0.52 \times \mathrm{a} \times \mathrm{b}^{2}$, with "a" representing the long diameter and " $\mathrm{b}$ " the short diameter. For the survival record, moribund mice or mice with tumors $>1000 \mathrm{~mm}^{3}$ upon the examination were recorded as dead and sacrificed for histological examination or western blotting.

\subsection{Histology, Immunohistochemistry and Immunofluorescence}

The tumors were collected from the mice after sacrifice and rinsed in $4 \%$ cold paraformaldehyde. Fixed tissue samples were embedded in paraffin, and slides were made for Hematoxylin and eosin (H\&E) staining and other immunohistochemistry or immunofluorescence. For immunohistochemistry staining, tumor tissue was divided and fixed in $4 \%$ paraformaldehyde overnight at $4{ }^{\circ} \mathrm{C}$, then ethanol overnight at $4{ }^{\circ} \mathrm{C}$ and processed to be embedded in paraffin blocks. Paraffin slides were dewaxed by xylene, followed by rehydrating through a series of washes with incrementally decreasing percentages of ethanol. Antigen retrieval was performed in $10 \mathrm{mM}$ sodium citrate buffer ( $\mathrm{pH} \mathrm{6.0)}$ by a placement microwave on high for $10 \mathrm{~min}$, followed by a 20-min cool down at room temperature. After a blocking step with the 5\% goat serum and avidin-biotin blocking kit (Vector Laboratories, Burlingame, CA, USA), the slides were incubated with antibodies: anti-Ki67 (Labvision, Fremont, CA, USA) at a 1:150 dilution overnight at $4{ }^{\circ} \mathrm{C}$; anti-Bmil (Bethyl) was at a 1:100 dilution overnight at room temperature. Slides were then subjected to $3 \%$ hydrogen peroxide for $10 \mathrm{~min}$ to quench endogenous peroxidase and, subsequently, the biotin-conjugated secondary antibody 1:400 dilution for $30 \mathrm{~min}$ at room temperature. Detection was performed with the ABC-Elite peroxidase kit (Vector Laboratories, Burlingame, CA, USA) by using the DAB substrate kit (DakoCytomation, Carpinteria, CA, USA). For cellular immunofluorescence, cells grown in the cover slip were fixed by $4 \%$ cold paraformaldehyde and 
penetrated by $0.1 \%$ Triton X-100 (Thermo, Rockford, IL, USA). Then, cells were incubated with primary antibody and fluorescence conjugated secondary antibody (Alexa Fluor, Invitrogen, Carlsbad, CA, USA). Antibodies and dilutions were used as follows: anti-BrdU 1:1000 (Millipore, Bedford, MA, USA), anti-Cyclin D1 1:1000 (Millipore).

\subsection{Microscopy}

Microscopic examination of cells or tissue section slides was performed with an Olympus SZX12 fluorescence microscope equipped with a digital camera and connected to a PC running MagnaFire 2.0 camera software (Optronics, Goleta, CA, USA). Pictures were taken at equal exposure times for each sample.

\subsection{Statistical Analysis}

All statistical analyses were performed using SPSS13.0 software (SPSS Inc., Chicago, IL, USA). The differences between groups were compared using the Student's $t$-test, and data were expressed as the mean $\pm \mathrm{SD}$. Values of $p<0.05$ were considered to be significant.

\section{Conclusions}

In the present study, we found that knockdown of the Bmil gene inhibits HCC tumorigenicity and proliferation in vivo, both in the onset period and the fast growing period of the neoplasm. We also found that Bmil knockdown inhibits the tumor growth by inducing cell cycle arrest and apoptosis. In summary, our results demonstrated that Bmil can be used as a potential treatment target for HCC.

\section{Acknowledgments}

This work was financially supported by the National Natural Science Foundation of China (No. 81101824, No. 81202095, No. 81370058, No. 81205553), the Wuhan Young Talents Program (No. 2013070104010042) and by the Natural Science Foundation of Hubei Province (No. 2012FFB02332).

\section{Author Contributions}

Chuanrui Xu, Shibo Qi and Bin Li designed the project and wrote the paper. Shibo Qi, Bin Li, Tan Yang, Yong Liu and Shanshan Cao conducted the experiments. Xingxing He, Lei Li and Peng Zhang provided technical assistance and materials.

\section{Conflicts of Interest}

The authors declare no conflict of interest.

\section{References}

1. Roberts, L.R. Sorafenib in liver cancer-Just the beginning. N. Engl. J. Med. 2008, 359, 420-422. 
2. Shariff, M.I.; Cox, I.J.; Gomaa, A.I.; Khan, S.A.; Gedroyc, W.; Taylor-Robinson, S.D. Hepatocellular carcinoma: Current trends in worldwide epidemiology, risk factors, diagnosis and therapeutics. Expert Rev. Gastroenterol. Hepatol. 2009, 3, 353-367.

3. Matsushita, E.; Unoura, M.; Kaneko, S.; Kobayashi, K. Risk factors for development of hepatocellular carcinoma in patients with liver cirrhosis associated with hepatitis $\mathrm{C}$ virus. Nihon Rinsho 1995, $53,727-730$.

4. Zaman, S.N.; Melia, W.M.; Johnson, R.D.; Portmann, B.C.; Johnson, P.J.; Williams, R. Risk factors in development of hepatocellular carcinoma in cirrhosis: Prospective study of 613 patients. Lancet 1985, 1, 1357-1360.

5. Feo, F.; Pascale, R.M.; Simile, M.M.; de Miglio, M.R.; Muroni, M.R.; Calvisi, D. Genetic alterations in liver carcinogenesis: Implications for new preventive and therapeutic strategies. Crit. Rev. Oncog. 2000, 11, 19-62.

6. Thorgeirsson, S.S.; Grisham, J.W. Molecular pathogenesis of human hepatocellular carcinoma. Nat. Genet. 2002, 31, 339-346.

7. Whittaker, S.; Marais, R.; Zhu, A.X. The role of signaling pathways in the development and treatment of hepatocellular carcinoma. Oncogene 2010, 29, 4989-5005.

8. Forner, A.; Llovet, J.M.; Bruix, J. Hepatocellular carcinoma. Lancet 2012, 379, 1245-1255.

9. Levy, L.; Renard, C.A.; Wei, Y.; Buendia, M.A. Genetic alterations and oncogenic pathways in hepatocellular carcinoma. Ann. N. Y. Acad. Sci. 2002, 963, 21-36.

10. Jacobs, J.J.; Kieboom, K.; Marino, S.; de Pinho, R.A.; van Lohuizen, M. The oncogene and Polycomb-group gene Bmil regulates cell proliferation and senescence through the INK4a locus. Nature 1999, 397, 164-168.

11. Park, I.K.; Qian, D.; Kiel, M.; Becker, M.W.; Pihalja, M.; Weissman, I.L.; Morrison, S.J.; Clarke, M.F. Bmil is required for maintenance of adult self-renewing haematopoietic stem cells. Nature 2003, 423, 302-305.

12. Molofsky, A.V.; Pardal, R.; Iwashita, T.; Park, I.K.; Clarke, M.F.; Morrison, S.J. Bmi1 dependence distinguishes neural stem cell self-renewal from progenitor proliferation. Nature 2003, 425, 962-967.

13. Park, I.K.; Morrison, S.J.; Clarke, M.F. Bmil, stem cells, and senescence regulation. J. Clin. Investig. 2004, 113, 175-179.

14. Jacobs, J.J.; Scheijen, B.; Voncken, J.W.; Kieboom, K.; Berns, A.; van Lohuizen, M. Bmi1 collaborates with c-Myc in tumorigenesis by inhibiting c-Myc-induced apoptosis via INK4a/ARF. Genes Dev. 1999, 13, 2678-2690.

15. Pietersen, A.M.; Horlings, H.M.; Hauptmann, M.; Langerod, A.; Ajouaou, A.; Cornelissen-Steijger, P.; Wessels, L.F.; Jonkers, J.; van de Vijver, M.J.; van Lohuizen, M. EZH2 and Bmi1 inversely correlate with prognosis and TP53 mutation in breast cancer. Breast Cancer Res. 2008, 10, R109.

16. Dhawan, S.; Tschen, S.I.; Bhushan, A. Bmil regulates the INK4a/ARF locus to control pancreatic beta-cell proliferation. Genes Dev. 2009, 23, 906-911.

17. Becker, M.; Korn, C.; Sienerth, A.R.; Voswinckel, R.; Luetkenhaus, K.; Ceteci, F.; Rapp, U.R. Polycomb group protein Bmil is required for growth of RAF driven non-small-cell lung cancer. PLoS One 2009, 4, e4230. 
18. Dovey, J.S.; Zacharek, S.J.; Kim, C.F.; Lees, J.A. Bmi1 is critical for lung tumorigenesis and bronchioalveolar stem cell expansion. Proc. Natl. Acad. Sci. USA 2008, 105, 11857-11862.

19. Bruggeman, S.W.; Hulsman, D.; Tanger, E.; Buckle, T.; Blom, M.; Zevenhoven, J.; van Tellingen, O.; van Lohuizen, M. Bmil controls tumor development in an INK4a/ARF-independent manner in a mouse model for glioma. Cancer Cell 2007, 12, 328-341.

20. Wang, E.; Bhattacharyya, S.; Szabolcs, A.; Rodriguez-Aguayo, C.; Jennings, N.B.; Lopez-Berestein, G.; Mukherjee, P.; Sood, A.K.; Bhattacharya, R. Enhancing chemotherapy response with Bmi1 silencing in ovarian cancer. PLoS One 2011, 6, e17918.

21. Qin, Z.K.; Yang, J.A.; Ye, Y.L.; Zhang, X.; Xu, L.H.; Zhou, F.J.; Han, H.; Liu, Z.W.; Song, L.B.; Zeng, M.S. Expression of Bmil is a prognostic marker in bladder cancer. BMC Cancer 2009, 9, 61.

22. Song, L.B.; Zeng, M.S.; Liao, W.T.; Zhang, L.; Mo, H.Y.; Liu, W.L.; Shao, J.Y.; Wu, Q.L.; Li, M.Z.; Xia, Y.F.; et al. Bmil is a novel molecular marker of nasopharyngeal carcinoma progression and immortalizes primary human nasopharyngeal epithelial cells. Cancer Res 2006, 66, 6225-6232.

23. Mohty, M.; Yong, A.S.; Szydlo, R.M.; Apperley, J.F.; Melo, J.V. The polycomb group Bmil gene is a molecular marker for predicting prognosis of chronic myeloid leukemia. Blood 2007, 110, 380-383.

24. Chiba, T.; Miyagi, S.; Saraya, A.; Aoki, R.; Seki, A.; Morita, Y.; Yonemitsu, Y.; Yokosuka, O.; Taniguchi, H.; Nakauchi, H.; et al. The polycomb gene product Bmil contributes to the maintenance of tumor-initiating side population cells in hepatocellular carcinoma. Cancer Res. 2008, 68, 7742-7749.

25. Xu, C.R.; Lee, S.; Ho, C.; Bommi, P.; Huang, S.A.; Cheung, S.T.; Dimri, G.P.; Chen, X. Bmi1 functions as an oncogene independent of INK4a/ARF repression in hepatic carcinogenesis. Mol. Cancer Res. 2009, 7, 1937-1945.

26. Chiba, T.; Seki, A.; Aoki, R.; Ichikawa, H.; Negishi, M.; Miyagi, S.; Oguro, H.; Saraya, A.; Kamiya, A.; Nakauchi, H.; et al. Bmil promotes hepatic stem cell expansion and tumorigenicity in both $I N K 4 a / A R F$-dependent and -independent manners in mice. Hepatology 2010, 52, 1111-1123.

27. Sparmann, A.; van Lohuizen, M. Polycomb silencers control cell fate, development and cancer. Nat. Rev. Cancer 2006, 6, 846-856.

28. Douglas, D.; Hsu, J.H.; Hung, L.; Cooper, A.; Abdueva, D.; van Doorninck, J.; Peng, G.; Shimada, H.; Triche, T.J.; Lawlor, E.R. Bmil promotes ewing sarcoma tumorigenicity independent of CDKN2A repression. Cancer Res. 2008, 68, 6507-6515.

29. Wiederschain, D.; Chen, L.; Johnson, B.; Bettano, K.; Jackson, D.; Taraszka, J.; Wang, Y.K.; Jones, M.D.; Morrissey, M.; Deeds, J.; et al. Contribution of polycomb homologues Bmil and Mel-18 to medulloblastoma pathogenesis. Mol. Cell Biol. 2007, 27, 4968-4979.

30. Fan, C.; He, L.; Kapoor, A.; Gillis, A.; Rybak, A.P.; Cutz, J.C.; Tang, D. Bmil promotes prostate tumorigenesis via inhibiting $\mathrm{p} 16^{\mathrm{INK} 4 \mathrm{a}}$ and $\mathrm{p} 14^{\mathrm{ARF}}$ expression. Biochim. Biophys. Acta 2008, 1782, 642-648.

31. Chiba, T.; Zheng, Y.W.; Kita, K.; Yokosuka, O.; Saisho, H.; Onodera, M.; Miyoshi, H.; Nakano, M.; Zen, Y.; Nakanuma, Y.; et al. Enhanced self-renewal capability in hepatic stem/progenitor cells drives cancer initiation. Gastroenterology 2007, 133, 937-950. 
32. Ruan, Z.P.; Xu, R.; Lv, Y.; Tian, T.; Wang, W.J.; Guo, H.; Nan, K.J. Bmi1 knockdown inhibits hepatocarcinogenesis. Int. J. Oncol. 2013, 42, 261-268.

33. Zhang, R.; Xu, L.B.; Yue, X.J.; Yu, X.H.; Wang, J.; Liu, C. Bmil gene silencing inhibits the proliferation and invasiveness of human hepatocellular carcinoma cells and increases their sensitivity to 5-fluorouracil. Oncol. Rep. 2013, 29, 967-974.

34. Wu, Z.; Min, L.; Chen, D.; Hao, D.; Duan, Y.; Qiu, G.; Wang, Y. Overexpression of Bmil promotes cell growth and resistance to cisplatin treatment in osteosarcoma. PLoS One 2011, 6, e14648.

35. Jagani, Z.; Wiederschain, D.; Loo, A.; He, D.; Mosher, R.; Fordjour, P.; Monahan, J.; Morrissey, M.; Yao, Y.M.; Lengauer, C.; et al. The Polycomb group protein Bmi1 is essential for the growth of multiple myeloma cells. Cancer Res. 2010, 70, 5528-5538.

36. Datta, S.; Hoenerhoff, M.J.; Bommi, P.; Sainger, R.; Guo, W.J.; Dimri, M.; Band, H.; Band, V.; Green, J.E.; Dimri, G.P. Bmi1 cooperates with H-Ras to transform human mammary epithelial cells via dysregulation of multiple growth-regulatory pathways. Cancer Res. 2007, 67, 10286-10295.

37. Hoenerhoff, M.J.; Chu, I.; Barkan, D.; Liu, Z.Y.; Datta, S.; Dimri, G.P.; Green, J.E. Bmi1 cooperates with H-Ras to induce an aggressive breast cancer phenotype with brain metastases. Oncogene 2009, 28, 3022-3032.

38. Lessard, J.; Sauvageau, G. Bmil determines the proliferative capacity of normal and leukaemic stem cells. Nature 2003, 423, 255-260.

39. Tward, A.D.; Jones, K.D.; Yant, S.; Cheung, S.T.; Fan, S.T.; Chen, X.; Kay, M.A.; Wang, R.; Bishop, J.M. Distinct pathways of genomic progression to benign and malignant tumors of the liver. Proc. Natl. Acad. Sci. USA 2007, 104, 14771-14776.

40. Wojtowicz, J.M.; Kee, N. BrdU assay for neurogenesis in rodents. Nat. Protoc. 2006, 1, 1399-1405.

(C) 2014 by the authors; licensee MDPI, Basel, Switzerland. This article is an open access article distributed under the terms and conditions of the Creative Commons Attribution license (http://creativecommons.org/licenses/by/4.0/). 